\title{
STUDY OF VARIATIONS OF CERVICAL SEGMENT OF INTERNAL CAROTID ARTERY
}

\author{
Mahendra Kumar Pant ${ }^{1}$, Jayanti Pant ${ }^{2}$
}

1. Department of Anatomy, Government Doon Medical College Dehradun, Uttarakhand, India 2. Department of Physiology, AlIMS, Rishikesh, Uttarakhand, India

\begin{abstract}
Introduction: Presence of variations in the course of the cervical (extracranial) part of the internal carotid artery (I.C.A.) in the form of tortuosity, kinking, coiling or looping is a rare condition. These may be attributed to embryological or acquired factors. Patients with such variations may be asymptomatic in some cases, whereas, they may develop cerebrovascular symptoms due to carotid stenosis affecting cerebral circulation.

Materials and methods: The present study was performed during routine undergraduate dissection classes in total 21 human cadavers (6 females and 15 males) on bilateral sides.

Results: Bilateral kinking and looping of the cervical part of the I.C.A. was found in two cadavers.

Conclusions: The risk of transient ischemic attacks (TIA) in patients with carotid stenosis is high and surgical correction is indicated as a part of treatment. Further, patients having these variations are more prone to injury during radical neck dissection and other surgical operations of the neck region. Knowledge about anatomy of such variations provides a framework to review the embryogenesis of the structure and also provides insight into surgical, medical and radiological implications.
\end{abstract}

Keywords: Looping, Internal carotid artery, Variations

\section{INTRODUCTION}

Neck is the vital area which contains major blood vessels supplying the brain. The Internal Carotid Artery (ICA), which constitutes a major medium of blood circulation to brain, is one of the terminal branches of the common carotid artery. ICA passes straight upward through the neck within the carotid sheath [1-3]. ICA generally comprises of four parts namely, cervical, petrous, cavernous and cerebral part. In Cervical region, ICA generally has a straight course and rarely gives any branch. ICA lies superficially in the carotid triangle and then takes a deep course medial to the posterior

Address for Correspondence:

Dr Mahendra Kumar Pant, Professor and Head, Department of Anatomy, Government Doon Medical College Dehradun, Uttarakhand (India) Email - pant.mahendra@gmail.com

Date of Receiving: 19 May 2020

Date of Acceptance: 24 June 2020

0970-1842/Copyright @ JAS 2020 
belly of digastric muscle. Carotid sinus is a bulbous enlargement located at the beginning of ICA and functions as a baroreceptor which regulates heart rate and blood pressure [3].

Variations in the cervical segment of ICA are said to be between 10 and $40 \%$ of the population. These variations are usually bilateral [4-9]. ICA variations have been observed in $4-66 \%$ in adults and $16-43 \%$ in children [10-13].

Sometimes, the cervical part of ICA may be tortuous especially when it is located closer to tonsil [4]. This makes the ICA prone to injury during surgical procedures like tonsillectomy, drainage of peritonsillar abscess, soft palate injuries, as well as adenoidectomy and velopharyngeoplasty [14-20].

The explanation for origin of such variations of ICA has been described by various researchers. Some studies report that the variations represent congenital vascular anomalies, whereas other studies correlate these variations to arteriosclerotic pathology or fibromuscular dysplasia [21,22].

Though there may be different explanations supporting the variations of ICA, their knowledge is important for the clinicians who deal with patients suffering from cerebrovascular diseases and surgeons who operate in head-neck region. In the present study, we discuss the variations of ICA, which were observed in cadavers while performing dissection to teach first year undergraduate students.

\section{MATERIALS AND METHODS}

The present study was conducted during routine educational dissection for undergraduate students. In this study, we explored 21 (twenty-one) cadavers which were formalin fixed. Dissection of cervical part of ICA was performed bilaterally (42 ICA) following standard procedure of dissection. To begin with, common carotid artery was identified by retracting the sternocleidomastoid. Then it was traced towards upper end of thyroid cartilage of larynx. At the upper end of thyroid cartilage, the common carotid artery (CCA) bifurcated into external and internal carotid artery. In the cervical segment, the origin of branches from ICA and distribution in the neck area were observed.

\section{RESULTS}

All formalin preserved 21 human cadavers were dissected on both right and left side (total 42 ICA were studied). Of these, variations were observed in cervical part of ICA in 2 male cadavers on bilateral sides (Table 1).

In one 60 year old male cadaver, we could observe the kinking and looping of cervical part in bilateral internal carotid artery. On right side, the internal carotid artery was found to arise from the common carotid artery at the level of upper border of thyroid cartilage. The artery coursed postero-superiorly up to the angle of mandible to make a loop (proximal) and then descended up to the greater cornu of hyoid bone to form another loop (distal). Finally it ascended supero-medially to reach the carotid canal (Fig. 1). 
On the left side, the ICA originated from CCA at the level of upper border of thyroid cartilage then coursed postero-superiorly up to the angle of mandible to make a loop (proximal) and then descended up to the greater cornu of hyoid bone to form another loop (distal). Finally, it ascended supero-medially to reach the carotid canal. Carotid sinus as dilatations were also observed on both sides. The loops of ICA on bilateral sides appeared as S-shaped loop (Fig. 2).

In another cadaver of about 69 year old male, we observed a different pattern of ICA on both left and right side. On right side, after origin from CCA, ICA travelled in a straight course in cervical region. External carotid artery (ECA) was located lateral to ICA. ICA did not give any branch from the cervical part (Fig. 3)

On left side, ICA had a tortuous course. Immediately after origin, it was dilated to form carotid sinus. Thereafter, the ICA travelled straight on the lateral side and became deeper (Fig. 4).

\section{DISCUSSION}

Exploration of anatomy of the neck region is essential for identification of the blood vessels. The CCA and its branches ECA \& ICA, act as an important landmark for neck dissection. ICA develops from third aortic arch and cranial part of dorsal aorta. During the process of development at around fifth and sixth embryonic weeks, a loop is formed where these two vessels meet.

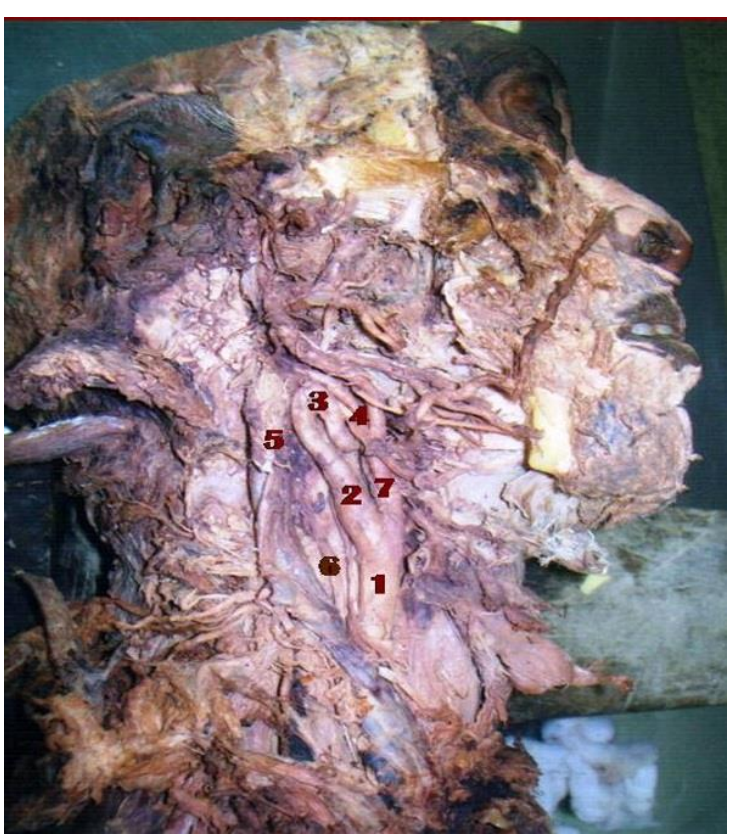

Fig. 1. Right Side Loops of Internal Carotid Artery in cadaver (60 year male) 1. Common Carotid Artery 2. Internal Carotid Artery 3. Proximal loop 4. Distal loop 5. Internal Jugular vein 6. Vagus nerve 7. External Carotid Artery

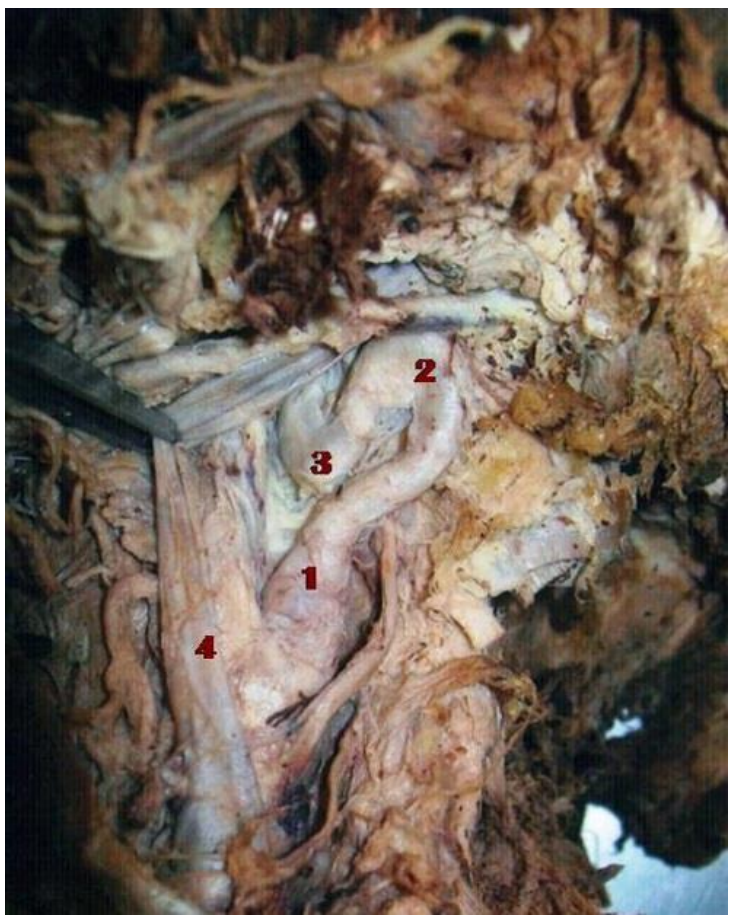

Fig. 2. Left Side S-shape Loop of Internal Carotid Artery in cadaver (60 year male). 1. Internal Carotid Artery 2. Proximal loop of Internal Carotid Artery 3. Distal loop of Internal Carotid Artery 4. Internal Jugular Vein 
At the same time, the heart and the large vessels descend into the mediastinal space, which causes straightening of the ICA. In case this development is affected at any phase, it leads to formation of a loop in the ICA. Most of the times, ICA follows a straight course in the cervical region but malformations of ICA are also common which alter the regular anatomy. Some vessels are longitudinally elongated and become tortuous. In our observation, in two cadavers we found tortuous and looped ICA.

S or C shaped loops and tortuosities are reported to arise due to embryological development of branchial arch arteries [5]. During development, large vessels descend into mediastinal space and this leads to elongation and straightening of arteries. Any obstruction in this process or excessive growth of artery may lead to the looping of artery. Elongation of vessels is attributed to traction of vessels by surrounding tissue which stretches the vessel and increase pressure inside the lumen of the vessel. Further, such variations have been often linked to increasing age, where arteriosclerosis, stenosis and loss of elasticity of arterial walls have been associated with the changes. The cadavers in our study were of elderly humans and the variations may be result of embryological malformation or age-related degenerative changes.

These variations are prone to cause cerebral ischemia or stroke. The change in diameter of lumen of the ICA leads to decrease in blood pressure to finally reduces cerebral circulation to cause TIA [23]. However, reduction in blood pressure leads to activation of baroreceptors

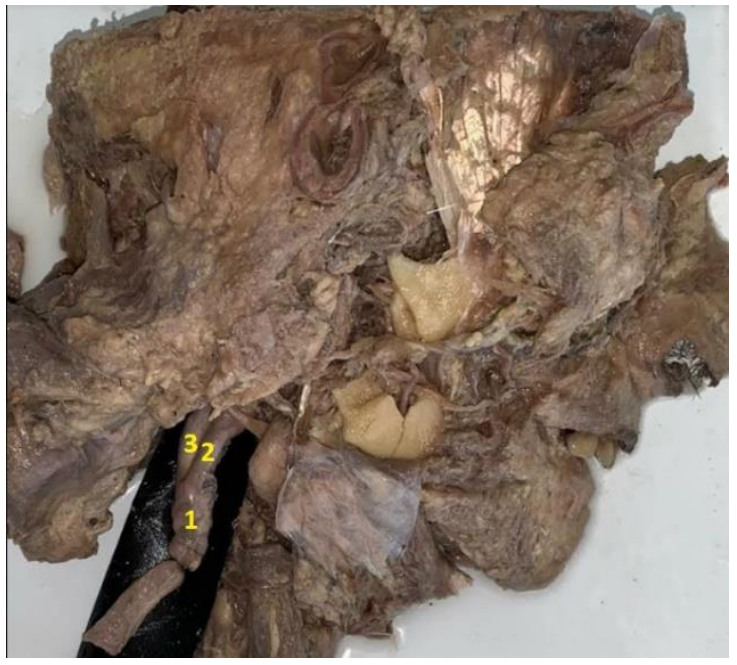

Fig. 3. Right Side of Internal Carotid Artery in cadaver (69 year male) 1. Common Carotid Artery 2. Internal Carotid Artery 3. External Carotid Artery

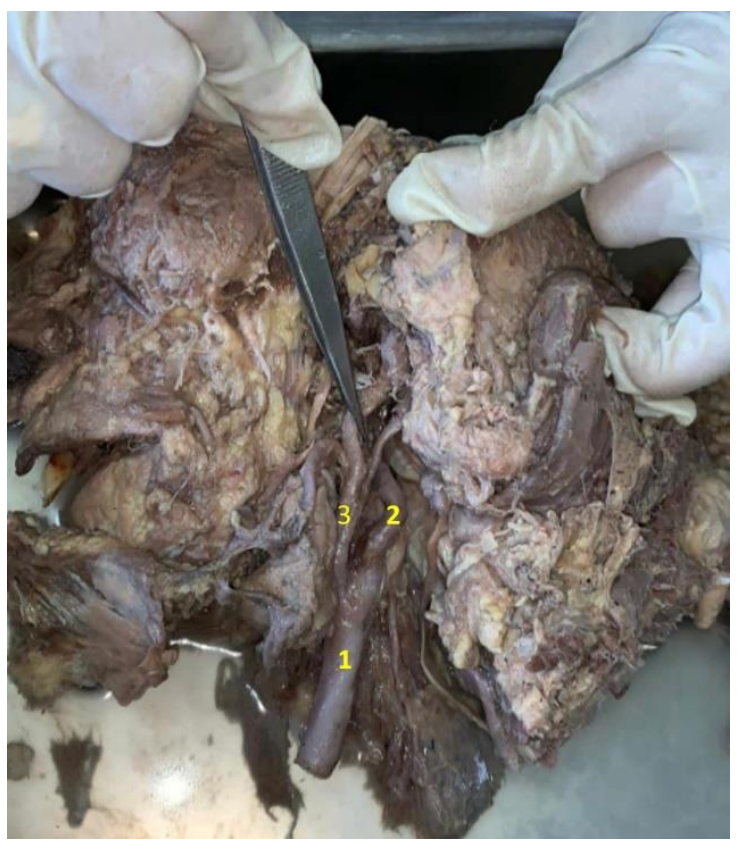

Fig. 4. Left Side of Internal Carotid Artery in cadaver (69 year male) 1. Common Carotid Artery 2. Internal Carotid Artery 3. External Carotid Artery

which try to compensate for change in pressure. Failure of the compensatory mechanisms may lead to decreased blood flow to brain. Further, studies have reported for association of tortuosity of ICA with increased BMI [24]. 
The presence of these variations in elderly population exposes them to a greater risk for TIA. Hence knowledge of these variations is pertinent for the surgeons, neurologists and radiologists who deal with cerebrovascular diseases.

\section{REFERENCES}

1. Henle J Handbuch der GefaX ûlehre des Menschen, vol. III. Braunschweig: Viehweg und Sohn.1868.

2. Von Lanz T, Wachsmuth W. Praktische Anatomie. Kopf, vol II, Berlin: Springer.1955.

3. Standring S. Gray's Anatomy: The Anatomical Basis of Clinical Practice, Vascular Supply and Drainage of the Brain, 41st Ed., Churchill Livingstone London; 2008; pp-455.

4. Cairney J. Tortuosity of the cervical segment of the internal carotid artery. Journal of Anatomy. 1924; 59: 87-96.

5. Metz H, Murray-Leslie RM, Bannister RG, Bull JWD, Marshall J. Kinking Of The Internal Carotid Artery In Relation To cerebrovascular disease. Lancet.1961; 1: 424-426.

6. Herrschaft $\mathrm{H}$. Zerebrale Durchblutungssto\$ rungen bei extremer Schlingenbildung der Arteria carotis interna. MuX nchner Medizinische Wochenschrift. 1968; 110: 2694-2702.

7. Herrschaft $H$ Abnorme Schlingenbildungen $\operatorname{der} A$. carotis interna und inre klinische Bedeutung bei Operationen im Halsbereich. Zeitschrift fuX $r$ Laryngologie und Rhinologie. 1969; 2: 85-98.

8. Brosig HJ, Vollmar J. Chirurgische Korrektur der Knickstenosen der A. carotis interna. MuX nchener Medizinische Wochenschrift. 1974; 116: 969-982.

9. Tillmann B, Christofides C. Die 'gefa $\$$ hrliche Schleife ' der Arteria carotis interna. HNO. 1995; 43: 601-604.
10.Desay B, Toole JF. Kinks, coils, and carotids: a review. Stroke. 1975; 6: 649-653.

11.Ghilardi G, Longhi F, De Monti M, Bortolani E. Kinking carotideo ed ipertensione arteriosa. Risultati preliminari del programma OPI. Minerva Cardioangiologica. 993; 41: 287-291.

12.Koskas F, Bahnini A, Walden R, Kieffer E. Stenotic coiling and kinking of the internal carotid artery. Annals of Vascular Surgery. 1993; 7: 530-540.

13.Leipzig TJ, Dohrmann GJ. The tortuous or kinked carotid artery: pathogenesis and clinical considerations. A historical review. Surgical Neurology. 1986; 25: 478-486.

14.Scillern PG. Anomalous internal carotid artery and its clinical signi®cance in operations on tonsils. Journal of the American Medical Association. 1913; 60: 172-173.

15. Fisher AGT. Sigmoid tortuosity of the internal carotid artery and its relation to tonsil and pharynx. Lancet. 1915; 2: 128130.

16. Jackson JL. Tortuosity of the internal carotid artery and its relation to tonsillectomy. Canadian Medical Association Journal. 1933; 29: 475-479.

17. Swoboda H, Czech T, Schindler E. Aberrierende Strombahn einer Arteria carotis interna durch das Mittelohr. HalsNasen-Ohrenheilkunde, Kopf- und HalsChirurgie. 1991; 39: 315-320.

18. Herrmann A. Gefahren bei Operationen am Hals, Ohr und Gesicht und die Korrektur fehlerhafter Eingriffe. Berlin: Springer.1965.

19.Jackel M. Verlaufsvarianten der A. carotis interna als Differentialdiagnose parapharyngealer Raumforderungen. HalsNasen-Ohrenheilkunde, Kopf- und HalsChirurgie. 1997;45: 1018-1021.

20.Schumacher WA, Schafig A, Kehrl W, Pau HW. Verlaufsvarianten der Arteria carotis interna: Mo\$ gliche Risiken bei sogenannten Standardoperationen im Pharynxbereich. 
Laryngologie, Rhinologie, Otologie. 1998; 77: 517-520.

21.Schenk P, Temmel A, Trattnig S, Kainberger F. Aktuelle Aspekte in der Diagnostik und Therapie des Karotiskinking. Hals-NasenOhrenheilkunde. Kopf and Hals Chirurgie. 1996; 44:178-185.

22.Friedrich $\mathrm{P}, \quad$ Bernhard $\mathrm{T}$, Christos $\mathrm{C}$,Walburga R, Jurgen K. Curving and looping of the internal carotid artery in relation to the pharynx: frequency, embryology and clinical implications. J. Anat. 2000; 197: 373-381.

23.Lijun $W$, Feng $Z$, Daming $W$, Shen $H$, Jiachun L, Zhilun Z, Jun L, Peng Q, Shiying S. Pressure Drop in Tortuosity/Kinking of the Internal Carotid Artery: Simulation and Clinical Investigation. BioMed Research International. 2016; 2016, Article ID 2428970, 8 pages http://dx.doi.org/10.1155/2016/2428970

24. Wang HF, Wang DM, Wang JJ, Wang LJ, Lu J, Qi P, Hu S, Yang ZM, Chen KP. Extracranial Internal Carotid Artery Tortuosity and Body Mass Index. Frontiers in Neurology. 2017; 8: Article 508. 